\title{
Evolving concepts of reflux: The ups and downs of the LES
}

\author{
Tom R DeMeester MD
}

TR DeMeester. Evolving concepts of reflux: The ups and downs of the LES. Can J Gastroenterol 2002;16(5):327-331.

The common denominator for virtually all episodes of gastroesophageal reflux in health and disease is the loss of the barrier that confines the gastric environment to the stomach. Factors important in the function of the barrier are its pressure, length and position. In early reflux disease, overeating, gastric distention, delayed emptying and aerophagia lead to transient losses of the barrier. A permanent loss results from inflammatory injury to the muscle of the barrier with free flow of gastric juice into the esophageal body and its subsequent injury. Corrective therapy requires augmentation or restoration of barrier function.

Key Words: Gastric distension; Gastroesophageal reflux disease; Lower esophageal sphincter
Nouveaux concepts relatifs au reflux : les hauts et les bas du sphincter inférieur de l'oesophage

RÉSUMÉ : Le dénominateur commun à presque tous les épisodes de reflux gastro-oesophagien, qu'ils se produisent chez une personne en santé ou malade, se résume à la perte de la barrière qui limite le milieu gastrique à l'estomac. Trois facteurs importants sont liés au fonctionnement de la barrière : la pression, la longueur et la position. Au début de la maladie, l'alimentation excessive, la distension gastrique, le retard de vidange et l'aérophagie entraînent des pertes temporaires d'étanchéité. Plus tard, ces pertes deviennent chroniques : le muscle de la barrière, affaibli par les lésions inflammatoires laisse passer le suc gastrique dans le corps de l'œsophage, qui est lésé à son tour. Le traitement curatif exige une amélioration du fonctionnement de la barrière ou son rétablissement.

\section{BIOMECHANICS OF THE ALIMENTARY TRACT}

The gastrointestinal tract is a continuous, hollow tube. Its functions are the ingestion and digestion of food, the absorption of chemical energy and the elimination of residue. These functions are performed separately in different compartments, whose boundaries differ from the customary anatomical divisions of the gastrointestinal tract.
Each compartment has a pumping mechanism to propel contents into a receptacle or reservoir portion of the compartment, and a sphincter to separate the pump from the reservoir. Each compartment has the ability to maintain a distinct chemical, enzymatic and $\mathrm{pH}$ environment within the reservoir appropriate to its function. In the most proximal compartment, the tongue and pharynx function as a

Department of Surgery, Keck School of Medicine, University of Southern California, Los Angeles, California

Correspondence and reprints: Dr Tom R DeMeester, Department of Surgery, Keck School of Medicine, University of Southern California, 1510 San Pablo Street, Suite 514, Los Angeles, California 90033-4612, USA. Telephone 323-442-5925, fax 323-442-5872,

e-mail demeester@surgery.hsc.usc.edu

Received for publication April 18, 2002. Accepted April 18, 2002 


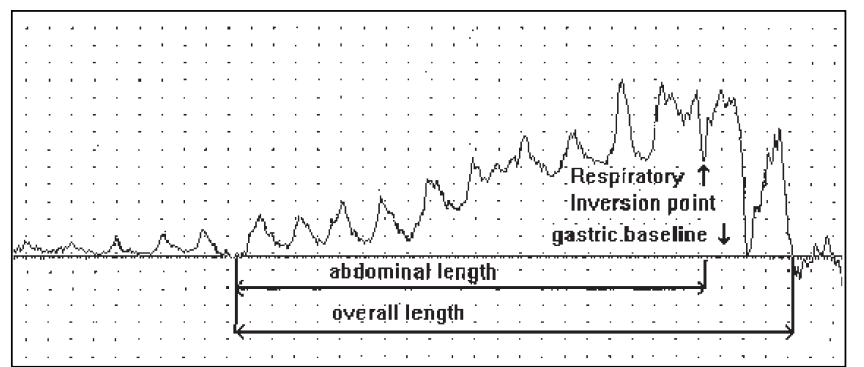

Figure 1) A pressure profile of the lower esophageal high pressure zone, or 'sphincter', measured in a normal subject. The high pressure zone has no anatomical landmarks but is identified by a rise in pressure over the gastric baseline as the pressure transducer is pulled from the stomach into the esophagus. Note the long intra-abdominal length identified by the positive respiratory excursions and the short intrathoracic length identified by the negative respiratory excursions. The point at which the respiratory excursions reverse is called the respiratory inversion point. Pressure scale is $3 \mathrm{mmHg}$ between vertical dots

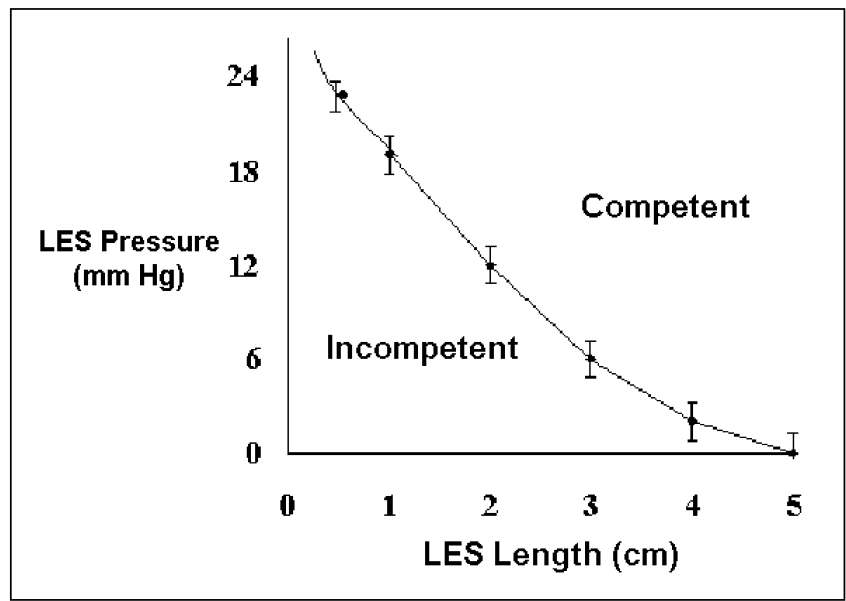

Figure 2) The relationship of the magnitude of pressure in the high pressure zone (measured at the respiratory inversion point) and the overall length of the zone, to the resistance to the flow of fluid through the zone. 'Competent' is no flow, and 'Incompetent' is flow of varied volumes. Note that the shorter the overall length of the high pressure zone, the higher the pressures must be to maintain sufficient resistance to remain competent. LES Lower esophageal sphincter

pump; the upper esophageal sphincter, soft palate and epiglottis function as valves; and the striated muscle portion of the upper esophagus functions as a receptacle. In the second compartment, the smooth muscle portion of the distal esophagus, characterized by peristaltic contractions of high amplitude, pumps food through a valve, the lower esophageal sphincter (LES), into the gastric fundus, which acts as a reservoir. In the third compartment, the antrum behaves as a pump, propelling chyme through a valve or sizer, the pylorus, into a receptacle, the duodenum. Similarly, the small intestine pumps its contents through the ileocecal valve into a capacitance organ, the cecum. An important principle is that the breakdown of function in one compartment of the gastrointestinal tract tends to produce secondary effects in the proximal compartments, rather than in the distal compartments. Thus, problems originating in the stomach commonly cause esophageal and pharyngolaryngeal symptoms (1). This concept is important in understanding the clinical presentation of gastroesophageal reflux disease (GERD). The principle pathophysiological abnormality responsible for these symptoms is the failure of the barrier or valve between the stomach and esophagus. The failure can be transient due to intermittent challenges of gastric distention or permanent due to inflammatory damage to the muscle of the LES and alteration in the geometry of the cardia.

\section{PHYSIOLOGY OF THE GASTROESOPHAGEAL BARRIER}

In humans, the barrier that confines the gastric environment to the stomach is the LES. It has no anatomical landmarks, but its presence can be identified by a rise in pressure over the gastric baseline pressure as a pressure transducer is pulled from the stomach into the esophagus (Figure 1). This high pressure zone is normally present, except in two situations: after a swallow, when it momentarily dissipates or relaxes to allow passage of a swallowed bolus into the stomach, and during a belch, when it allows gas to be vented from a distended fundus. The common denominator for virtually all episodes of gastroesophageal reflux is the loss of the normal high pressure zone or barrier. When the barrier is absent, resistance to the flow of gastric juice from an environment of higher pressure - the stomach - to an environment of lower pressure - the esophagus - is lost. In early disease, this is usually due to a transient loss of the barrier. In advanced disease, this is usually due to a permanent loss of the barrier (1).

There are three characteristics of this high pressure zone, commonly referred to as the LES, that maintain its function as a barrier to intragastric and intra-abdominal pressure challenges (Figure 1). Two of these characteristics - the overall length of the sphincter and the sphincter pressure work together and depend on each other to provide resistance to the flow of gastric juice from the stomach into the esophagus. Critical to this function is the overall length of the LES and the pressure measured over that length (2). The shorter the overall length, the higher the pressure must be for the sphincter to maintain sufficient resistance to remain competent (Figure 2). Consequently, the effect of a normal sphincter pressure can be nullified by a short overall sphincter length, and the effect of a normal overall sphincter length can be nullified by a low sphincter pressure.

For practical purposes, the pressure of the sphincter is measured at a single point - the respiratory inversion point - but in actuality, pressure is applied over the entire length of the sphincter. A more accurate assessment of barrier resistance is to measure the radial pressure exerted in four quadrants over the entire length of the sphincter. This allows the computer formation of a three-dimensional image of the sphincter or barrier (Figure 3). The volume of this image reflects the sphincter's resistance to the flow of fluid through it. This is called the 'sphincter pressure vector 


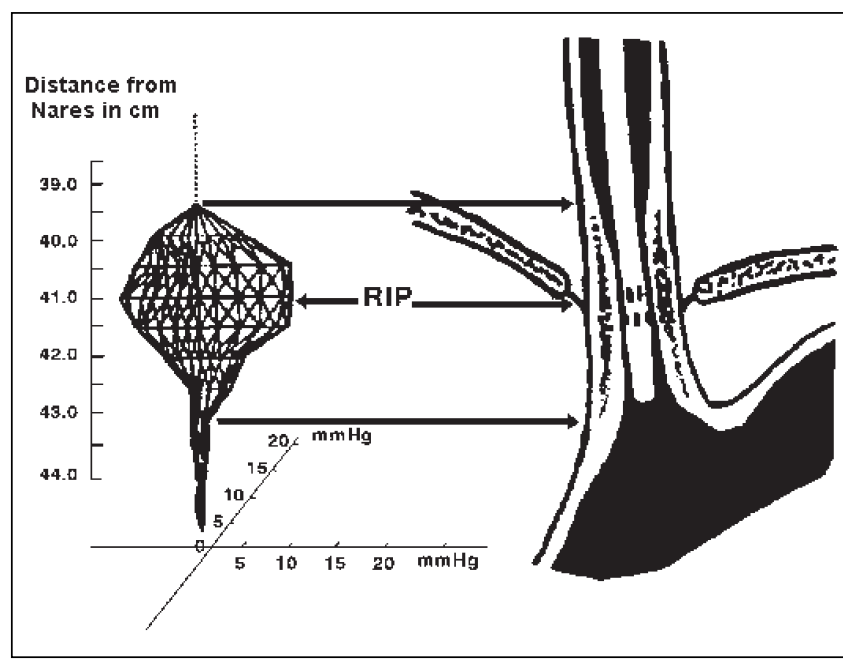

Figure 3) A graphic illustration of how a three-dimensional computerized image of the 'sphincter' can be constructed by measuring the pressure of the high pressure zone in four quadrants at $1 \mathrm{~cm}$ intervals over the entire length of the zone. The volume of the image reflects the resistance of the 'sphincter' to the flow of gastric juice into the esophagus, and is called the 'sphincter pressure vector volume'. Reprinted with permission from reference 3. RIP Respiratory inversion point

volume'. A calculated volume less than the fifth percentile of normal resting subjects is an indication of a permanently defective sphincter (3).

The fundamental principle is that the length of the sphincter is important to its function as a barrier (4). Shortening of the length of the sphincter occurs naturally with gastric filling, as the terminal esophagus is 'taken up' by the expanding fundus. This is similar to the shortening of the neck of a balloon as it is inflated. With extensive gastric distention, the length of the sphincter shortens to a critical point at which it gives way, the pressure drops precipitously and reflux occurs (Figure 4). If the length of the sphincter is permanently short, then further shortening caused by the normal gastric distention with meals will result in postprandial reflux. In this situation, gastroesophageal reflux is an ever-constant clinical problem.

The observation that gastric distention results in shortening of the sphincter down to a critical length, so that the pressure dissipates, the lumen opens and reflux occurs, provides a mechanical explanation for 'transient sphincter relaxation' without invoking a neuromuscular reflex. If only the sphincter pressure and not its length is measured, as with a Dent sleeve, the event will appear as a spontaneous relaxation of sphincter pressure (5). In reality, it is the progressive shortening of the sphincter, rather than transient relaxations, that results in the loss of sphincter pressure.

The third characteristic of the lower esophageal highpressure zone or 'sphincter' is its position. A portion of the overall length of the high pressure zone is normally exposed to positive intra-abdominal pressure and is commonly referred to as the abdominal length of the sphincter (Figure 1) (6). During periods of increased intra-abdominal

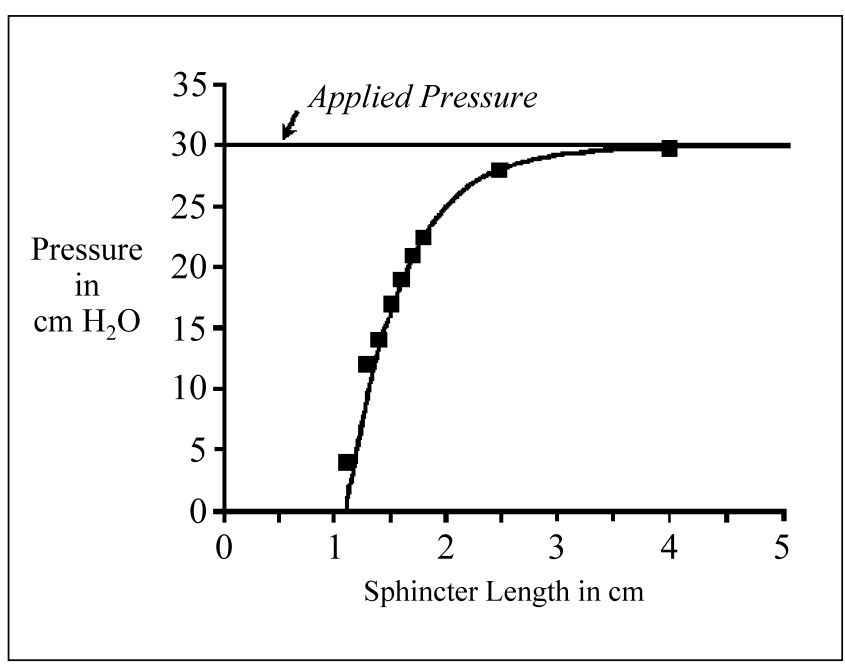

Figure 4) The relationship between resting sphincter pressure and sphincter length when applied pressure or 'sphincter squeeze' is kept constant. Analysis was made with a model of the lower esophageal highpressure zone. Note that, as the sphincter length decreases, the pressure recorded within the sphincter decreases only slightly, until a length of $2 \mathrm{~cm}$ is reached, at which point the sphincter pressure drops precipitously and competency of the sphincter is lost. Reprinted with permission from reference 4

pressure, the resistance of the LES would easily be overcome if the position of the sphincter were such that abdominal pressure were unable to be applied equally to the sphincter and stomach (7-9). Think of sucking on a soft soda straw immersed in a bottle of coke; the hydrostatic pressure of the fluid and the negative pressure inside the straw due to sucking cause the straw to collapse instead of allowing the liquid to flow up the straw in the direction of the negative pressure. If the sphincter is positioned so that the abdominal length is inadequate, the sphincter cannot collapse in response to applied positive intra-abdominal pressure and the negative intrathoracic pressure will encourage reflux to occur.

If a sphincter, in the fasting state, has abnormally low pressure, a short overall length or a minimal length exposure to the abdominal pressure environment, the result is a permanent loss of resistance and the unhampered reflux of gastric contents into the esophagus. This is known as a permanently defective sphincter and is identified by one or more of the following characteristics: an average pressure of less than $6 \mathrm{mmHg}$, an average overall length of $2 \mathrm{~cm}$ or shorter and an average length exposed to the positive pressure environment of the abdomen of $1 \mathrm{~cm}$ or shorter. Compared with normal subjects, these values are below the 2.5 percentile for each parameter (10). The common consequence of a permanently defective sphincter is increased esophageal exposure to gastric juice, mucosal injury, inflammation of the muscularis propria, and reduced contraction amplitude and abnormal wave forms in the esophageal body. If the reflux is not brought under control, the progressive loss of effective esophageal clearance results in an everincreasing esophageal acid exposure (11-13). 


\section{CAUSES FOR FAILURE OF THE GASTROESOPHAGEAL BARRIER}

Transient losses of the barrier are most commonly seen in early reflux disease and are associated with gastric distention (14). The ingestion of air and food results in gastric distention, and the vectors produced by the gastric wall tension pull on the gastroesophageal junction. This causes the terminal esophagus to be 'taken up' into the stretched fundus, thereby reducing the length of the sphincter. With overeating, a critical length is reached, usually about 1 to $2 \mathrm{~cm}$, at which point the sphincter gives way, its pressure drops precipitously and reflux occurs (Figure 4) (4). After gastric venting, the length of the sphincter is restored and competency returns, until distention again shortens it and encourages further venting and reflux. Patients with GERD swallow more frequently in an effort to neutralize the acid refluxed into the esophagus with their saliva. This results in the ingestion of more air and adds to the gastric distention (15). Together, the actions of overeating and swallowing air result in the common complaint of postprandial bloating, repetitive belching and heartburn in patients with early GERD. The high prevalence of the disease in the Western world is thought to be secondary to the eating habits of Western society (16). Gastric distention from overeating and delayed gastric emptying secondary to the increased ingestion of fried foods leads to prolonged periods of postprandial gastric distention, shortening of the sphincter and repetitive transient loss of the barrier. A Nissen fundoplication prevents the shortening of the barrier with progressive degrees of gastric distention by interrupting the vectors produced by gastric wall tension that pull on the gastroesophageal junction (17). The new endoscopic procedures, Endocinch (Bard, USA) and the Plicator (NDO Surgical, USA), attempt to do the same. Similarly, endoscopic injection of inert materials into the area of the barrier or scarring it with radiofrequency injury attempts to do this by reducing the compliance of the LES, making it more resistant to the pull of gastric wall tension.

In advanced reflux disease, permanent loss of sphincter length occurs from inflammatory injury that extends from the mucosa into the muscular layers of the distal esophagus. Fletcher et al (18) showed that, in the fasting state, there is a persistent region of high acidity in the area of the gastroesophageal junction and that this region of acidity migrates $2 \mathrm{~cm}$ proximally after meals. This migration was shown to occur as a result of distention of the stomach with eating and pulling apart of the distal high pressure zone, allowing the area of high acidity to move proximal to the squamocolumnar junction (18). This proximal movement exposes the distal esophageal squamous mucosa to acid, with the formation of cardiac mucosa $(19,20)$. Cardiac mucosa is an acquired mucosa and results from inflammatory injury to the squamous mucosa in the terminal esophagus. This inflammatory process extends into the muscular layer of the esophagus, resulting in the loss of muscle cells and permanent shortening of the high pressure zone, and a concomitant reduction in the amplitude of the high pressure zone or barrier pressure $(1,19-21)$. Such a defective barrier is recognized when the length or pressure of the sphincter measured during a motility study done in the fasting state is below the 2.5th percentile of normal (10).

For the clinician, the finding of a permanently defective barrier has several implications. Patients with this abnormality can be difficult to control with medical therapy (22). The damage is irreversible, and is commonly associated with reduced esophageal body contractility and abnormal wave progression (23). Under this condition, if reflux is not controlled, the progressive loss of effective esophageal clearance can lead to Barrett's metaplasia, repetitive regurgitation, aspiration and pulmonary fibrosis $(12,19,24,25)$.

Surgery is usually required in patients with GERD and a permanently defective barrier to obtain consistent long term symptom relief and interrupt the natural history of the disease. In this situation, the length and pressure of the barrier can be restored to normal by a laparoscopic Nissen fundoplication. At present, the newer endoscopic procedures do not appear to improve a permanently defective sphincter significantly. Critical to the long term success of laparoscopic surgical therapy for this degree of disease is that marked shortening of the esophagus has not occurred from inflammatory injury of the mucosa (13). If it has, there is too much tension on the laparoscopic repair, and breakdown is common. In this situation, an open procedure that completely mobilizes the thoracic esophagus or lengthens the esophagus with a gastroplasty provides a better long term outcome (19).

Variations in the anatomy of the cardia, from a normal acute angle of His to the abnormal dome architecture of a sliding hiatal hernia, influences the ease with which the sphincter is shortened by gastric distention. Consequently, alteration in the geometry of the cardia facilitates the loss of barrier function. Greater gastric distention is necessary to open the sphincter in patients with an intact angle of His than in those with a hiatal hernia (25). This is because the dome or funnel shape of a hiatal hernia allows the wall tension forces that pull open the sphincter to be more effectively applied to the gastroesophageal junction (26). This accounts for the common association of a hiatal hernia with GERD. The geometry of the hernia puts the sphincter at a mechanical disadvantage in maintaining its length, with progressive degrees of gastric distention. Kahrilas et al (27) demonstrated this mechanical disadvantage by studying the effect of intragastric air infusion on the number of transient LES relaxations (TLESRs)/h. Patients with hiatal hernia had significantly more TLESRs/h than control subjects and those without hernias. Intragastric distention with air infusion resulted in a gradual shortening of the sphincter in all three groups. This change became significant 20 to $30 \mathrm{~min}$ after the beginning of air infusion. Kahrilas et al (27) observed that the high pressure zone shortened before detection of the TLESR in the more proximal part of the zone. These findings support the concept that transient sphincter shortening, rather than sphincter relaxation, is the mechanism for barrier loss with gastric distention. 


\section{SUMMARY}

Almost all reflux episodes in normal subjects are precipitated by gastric distention. In patients, gastric distention from overeating and aerophagia is the cause of early GERD and remains an important but decreasing cause of reflux as the severity of the disease, reflected by the grade of esophagitis, worsens. The increased esophageal acid exposure in patients with early disease is due to transient loss of the barrier secondary to shortening of the sphincter with gastric distention. Mucosal damage from exposure to gastric juice results in an inflammatory injury of underlying sphincter muscle and leads to a permanent loss of the barrier, initially due to the loss of its abdominal length and eventually its overall length and pressure. Free flow of gastric juice into the esophagus results in subsequent inflammatory injury of the mucosa and muscle of the esophagus body, leading to the loss of its clearance ability and to prolonged esophageal exposure to gastric juice. This signals the presence of advanced disease and places the patient at risk for Barrett's metaplasia, stricture formation and aspiration (Figure 5).

\section{REFERENCES}

1. DeMeester TR, Ireland AP. Gastric pathology as an initiator and potentiator of gastroesophageal reflux disease. Dis Esophagus 1997;10:1-8.

2. Bonavina L, Evander A, DeMeester TR, et al. Length of the distal esophageal sphincter and competency of the cardia. Am J Surg 1986;151:25-34.

3. Stein HJ, DeMeester TR, Naspetti R, Jamieson J, Perry RE. Three-dimensional imaging of the lower esophageal sphincter in gastroesophageal reflux disease. Ann Surg 1991;214:374-84.

4. Pettersson GB, Bombeck CT, Nyhus LM. The lower esophageal sphincter: mechanisms of opening and closure. Surgery 1980;88:307-14.

5. Dent J. A new technique for continuous sphincter pressure measurement. Gastroenterology 1976;71:263-7.

6. DeMeester TR, Wernly JA, Bryant GH, Little AG, Skinner DB. Clinical and in vitro analysis of gastroesophageal competence: a study of the principles of antireflux surgery. Am J Surg 1979;137:39-46.

7. Pellegrini CA, DeMeester TR, Skinner DB. Response of the distal esophageal sphincter to respiratory and positional maneuvers in humans. Surg Forum 1976;27:380-2.

8. O'Sullivan GC, DeMeester TR, Joelsson BE, et al. Interaction of lower esophageal sphincter pressure and length of sphincter in the abdomen as determinants of gastroesophageal competence. Am J Surg 1982;143:40-7.

9. Johnson LF, Lin YC, Hong SK. Gastroesophageal dynamics during immersion in water to the neck. J Appl Physiol 1975;38:449-54.

10. Zaninotto G, DeMeester TR, Schwizer W, Johansson K-E, Cheng SC. The lower esophageal sphincter in health and disease. Am J Surg 1988;155:104-11.

11. Stein HJ, Barlow AP, DeMeester TR, Hinder RA. Complications of gastroesophageal reflux disease. Role of the lower esophageal sphincter, esophageal acid and acid/alkaline exposure, and duodenogastric reflux. Ann Surg 1992;216:35-43.

12. Tsai P, Peters J, Johnson W, Cohen R, Starnes V. Laparoscopic fundoplication 1 month prior to lung transplantation. Surg Endosc 1996;10:668-70.

13. Zaninotto G, DeMeester TR, Bremner CG, Smyrk TC, Cheng S-C. Esophageal function in patients with reflux-induced strictures and its relevance to surgical treatment. Ann Thorac Surg 1995;47:362-70.

14. Barham CP, Gotley DC, Mills A, Alderson D. Precipitating causes of

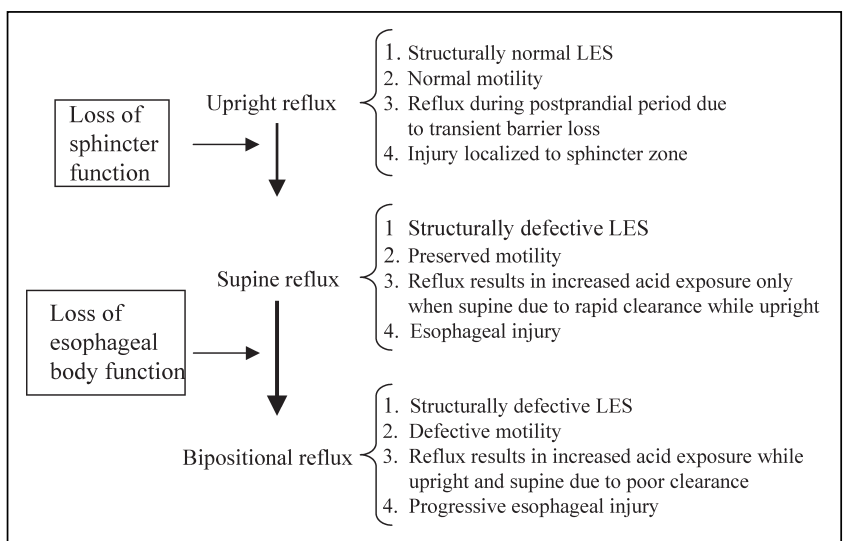

Figure 5) Schema of the progression of gastroesophageal reflux disease. Initially, esophageal acid exposure occurs only in the upright awake position after meals due to gastric distension causing transient losses of the barrier. With inflammatory injury to the lower esophageal sphincter (LES), the barrier becomes permanently defective, and an increase in esophageal acid exposure occurs in the supine position, while the esophageal body effectively clears the refluxed acid during the day when upright. Inflammatory injury to the esophageal body results in loss of esophageal body clearance function or bipositional reflux

acid reflux episodes in ambulant patients with gastro-oesophageal reflux disease. Gut 1995;36:505-10.

15. Bremner RM, Hoeft SF, Costantini M, Crookes PF, Bremner CG, DeMeester TR. Pharyngeal swallowing. The major factor in clearance of esophageal reflux episodes. Ann Surg 1993;218:364-9.

16. Iwakiri K, Kobayashi M, Kotoyari M, Yamada H, Sujiura T, Nakagawa Y. Relationship between postprandial esophageal acid exposure and meal volume and fat content. Dig Dis Sci 1996;41:926-30.

17. Mason RJ, DeMeester TR, Lund RJ, et al. Nissen fundoplication prevents shortening of the sphincter during gastric distention. Arch Surg 1997;132:719-26.

18. Fletcher J, Wirz A, Young J, et al. Unbuffered highly acidic gastric juice exists at the gastroesophageal junction after a meal. Gastroenterology 2001;121:775-83.

19. DeMeester TR, Peters JH, Bremner CG, Chandrasoma P. Biology of gastroesophageal reflux disease: pathophysiology relating to medical and surgical treatment. Ann Rev Med 1999;50:469-506.

20. Oberg S, Peters JH, DeMeester TR, et al. Inflammation and specialized intestinal metaplasia of cardiac mucosa is a manifestation of gastroesophageal reflux disease. Ann Surg 1997;226:522-32.

21. Theisen J, Öberg S, Peters JH, et al. Gastro-esophageal reflux disease confined to the sphincter. Dis Esophagus 2001;14:235-8.

22. Kuster E, Ros E, Toledo-Pimentel V, Pujol A, Bordas JM, Pera C. Predictive factors of the long term outcome in gastro-oesophageal reflux disease: six year follow up of 107 patients. Gut 1994;35:8-14.

23. Singh P, Adamopoulos A, Taylor RH, Colin-Jones DG. Oesophageal motor function before and after healing of oesophagitis. Gut 1992;33:1590-6

24. Stein HJ, Eypasch EP, DeMeester TR, Smyrk TC. Circadian esophageal motor function in patients with gastroesophageal reflux disease. Surgery 1990;108:769-78.

25. Ismail T, Bancewicz J, Barlow J. Yield pressure, anatomy of the cardia and gastroesophageal reflux. Br J Surg 1995;82:943-7.

26. Marchand $\mathrm{P}$. The gastro-oesophageal 'sphincter' and the mechanism of regurgitation. Br J Surg 1955;42:504-13.

27. Kahrilas PJ, Shi G, Manka M, Joehl RJ. Increased frequency of transient lower esophageal sphincter relaxation induced by gastric distention in reflux patients with hiatal hernia. Gastroenterology 2000;118:688-95. 


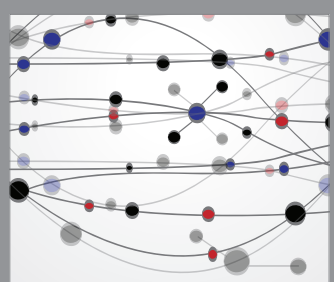

The Scientific World Journal
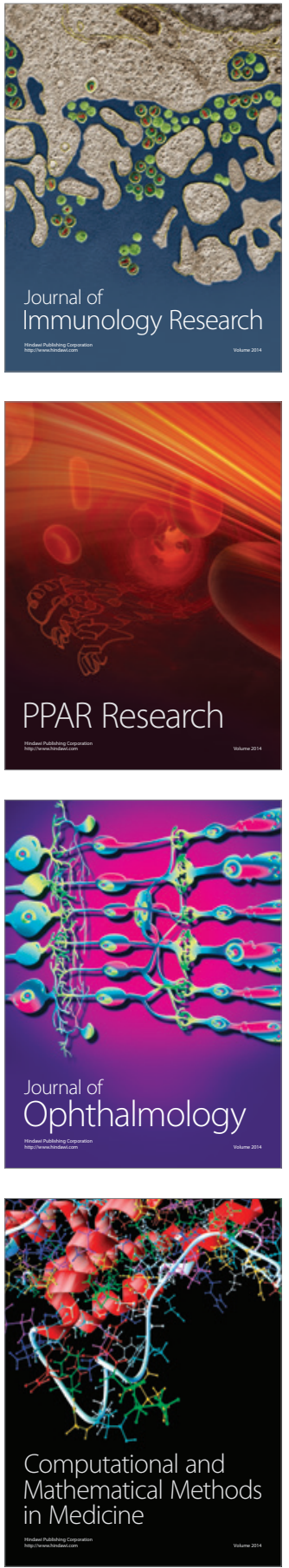

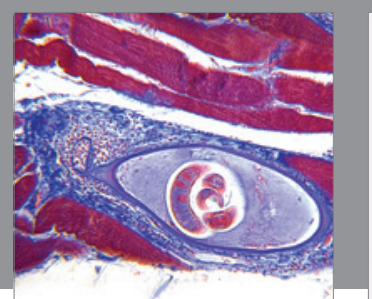

Gastroenterology Research and Practice

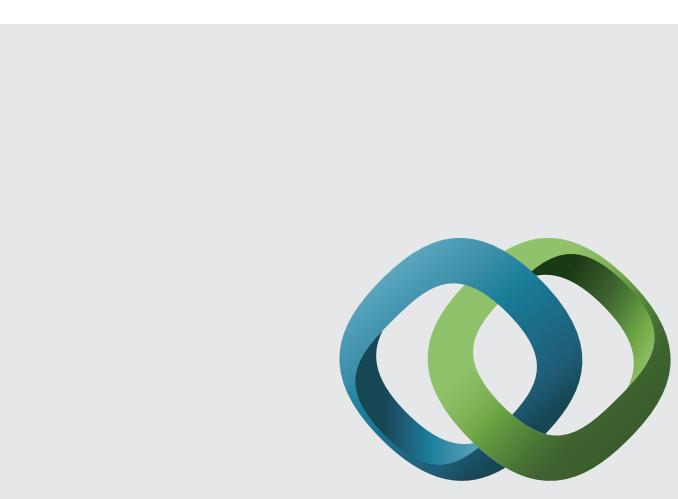

\section{Hindawi}

Submit your manuscripts at

http://www.hindawi.com
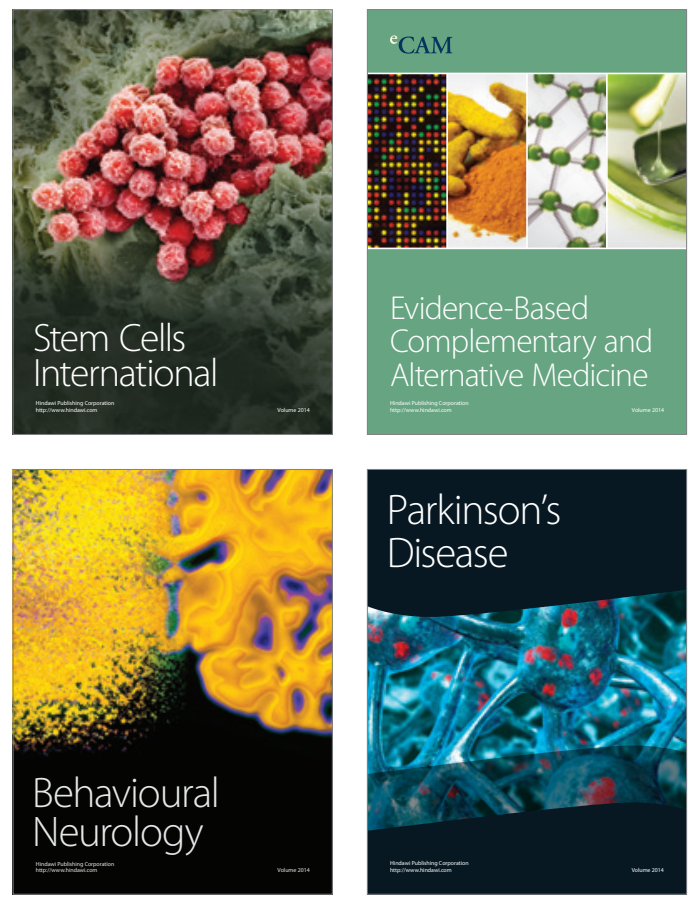
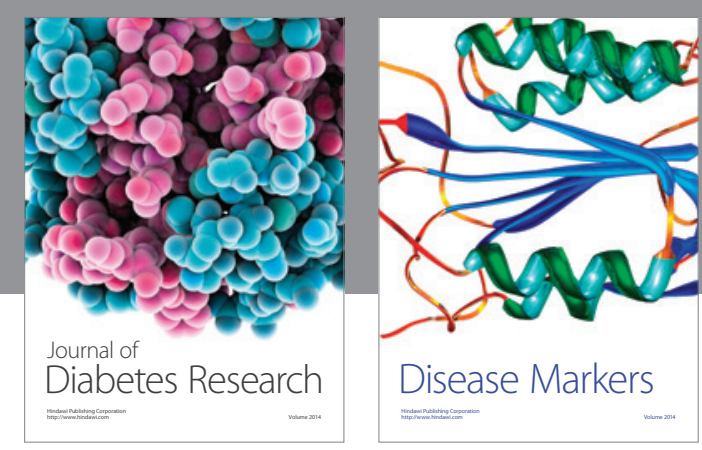

Disease Markers
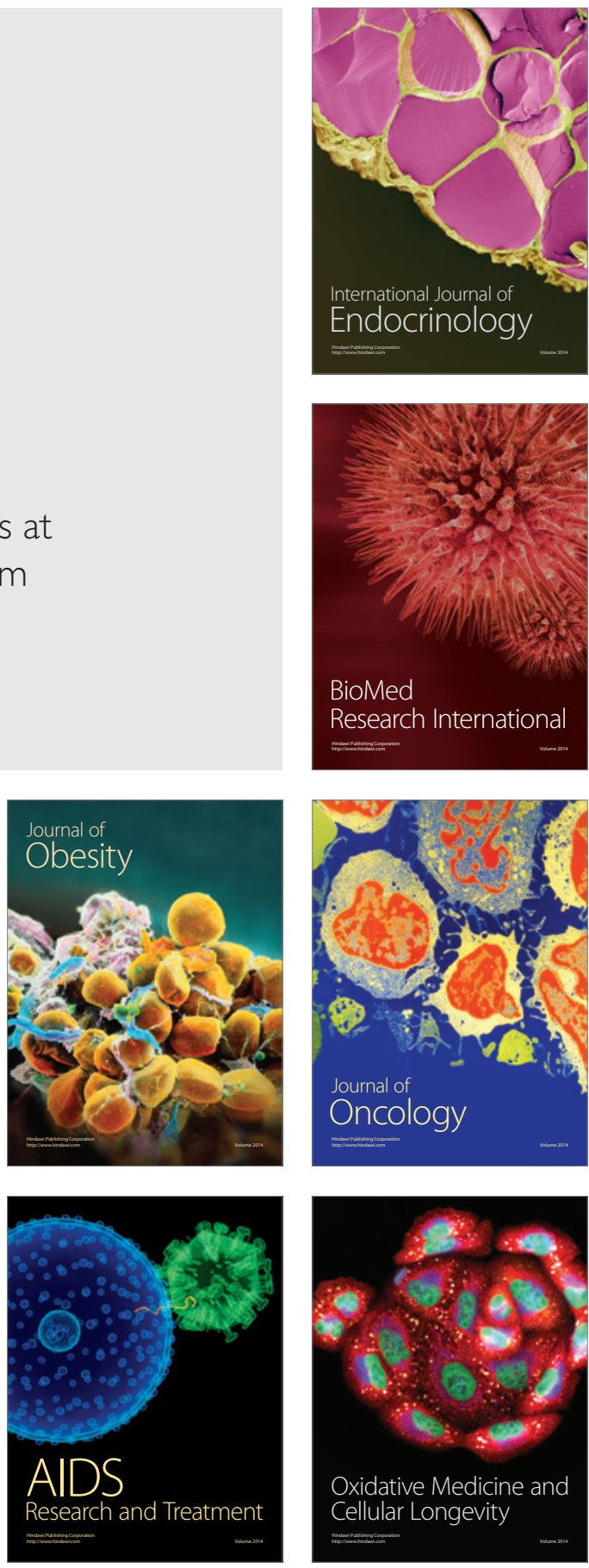